SAND94-2862C

\title{
PERFORMANCE CHARACTERIZATION OF THE NASA STANDARD DETONATOR ${ }^{*}$
}

\author{
William W. Tarbell \\ Explosives Projects and Diagnostics Department \\ Sandia National Laboratory \\ Albuquerque, NM 87185
}

Terence L. Burke and Steve E. Solomon

Component Engineering

USBI

Huntsville, AL 35807

\begin{abstract}
The NASA Standard Detonator (NSD) is employed in support of a number of current applications, including the Space Shuttle. This effort was directed towards providing test results to characterize the output of this device for its use in a safe and arm device. As part of the investigation, flash X-ray was used to provide stop-motion photographs of the flying metal plate that is created by initiation of the detonator. This provided researchers with a better understanding of the shape and character of the highvelocity disk as it propagated across the gap between the detonator and next assembly. The second portion of the study used a velocity interferometer to evaluate the acceleration and velocity histories of the flying plate, providing a quantified assessment of the detonator's ability to initiate the explosive in the next explosive.
\end{abstract}

\section{Introduction}

The safe and arm device (S \& A) on the Space Shuttle is designed to prevent inadvertent initiation of an explosive train, even in the unlikely event of premature detonator function. The design under consideration here consists of a detonator, transfer charge, shaft and barrier, and output device. The "safe" function is achieved by rotating the transfer charge into a position where it is not exposed to the output of the detonator. Because of the massive construction of the rotor, the detonator cannot penetrate through the body to strike the output lead.

This paper is declared a work of the U.S. Government and is not subject to copyright protection in the United States.
The NASA Standard Detonator (NSD) has been in use for a number of years (Figure 1). It consists of an output body attached to an electric initiator (NASA Standard Initiator or NSI). The output section has a diameter of approximately 0.25 " and contains the explosives lead azide (a primary compound) and the relatively insensitive material RDX. When properly functioned, the explosive is intended to cause the end closure to accelerate to high velocity across a gap to impact the next assembly.

The objective of this study is to provide information regarding the performance of the NSD. The impetus for the effort was provided by a

This work supported by the United states Department of Energy under Contract DE-AC04-94AL85000. 


\section{DISCLAIMER}

This report was prepared as an account of work sponsored by an agency of the United States Government. Neither the United States Government nor any agency thereof, nor any of their employees, make any warranty, express or implied, or assumes any legal liability or responsibility for the accuracy, completeness, or usefulness of any information, apparatus, product, or process disclosed, or represents that its use would not infringe privately owned rights. Reference herein to any specific commercial product, process, or service by trade name, trademark, manufacturer, or otherwise does not necessarily constitute or imply its endorsement, recommendation, or favoring by the United States Government or any agency thereof. The views and opinions of authors expressed herein do not necessarily state or reflect those of the United States Government or any agency thereof. 


\section{DISCLAIMER}

Portions of this document may be illegible in electronic image products. Images are produced from the best available original document. 
desire to consider removing the transfer charge from the $S \& A$, resulting in a cost savings, and increased safety by reducing the amount of explosive required. In order to accomplish this task, it was considered necessary to characterize the NSD using velocity interferometry and flash Xray. Together, these two diagnostics can determine the speed of the flying disk as a function of propagation distance and its physical character.

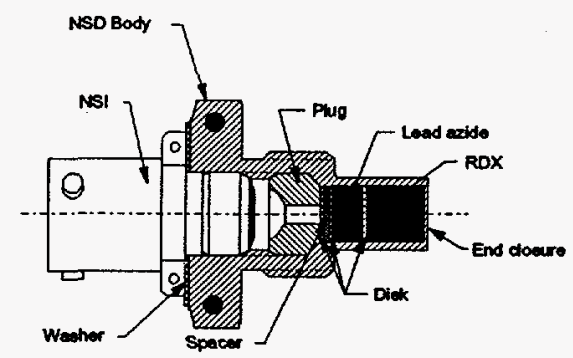

Figure 1. Schematic of NASA Standard Detonator

\section{Description of Components}

The NSD consists of the NSI screwed into an output section. The NSI is described elsewhere.' The explosives in the output section consist of approximately $374 \mathrm{mg}$ of lead azide and $400 \mathrm{mg}$ of RDX (hexahydro-1,3,5-trinitro-1,3,5-triazine), pressed into a machined stainless steel housing. The output of the NSI is presumed to be hot gas and particles that are focused through the stainless steel plug to impinge upon a thin aluminum disk. Upon failure of the disk, an underlying plastic spacer and a second disk, the debris contact a lowdensity increment (5-7.5 ksi pressing pressure) of the primary explosive lead azide. The detonation of the lead azide creates a low-intensity shock front traveling through the unreacted material at about $5.5 \mathrm{~mm} / \mathrm{ss}^{2}$. The RDX output charge is pressed at 10 to $15 \mathrm{ksi}$ and is intended to be promptly initiated when the shock front reaches the lead azide/RDX interface. It is estimated that the detonation of the RDX creates a high-intensity shock wave (about $400 \mathrm{kBar}$ ), traveling at a velocity of over $9 \mathrm{~mm} / \mu \mathrm{s}$.

When the RDX detonation front reaches the end closure, the metal separates from the surrounding material and is accelerated to high velocity. It is assumed that the diameter of the resulting metal disk matches the explosive column (about 0.24") and retains the original thickness of $0.015-0.020^{\prime \prime}$. The remainder of the output housing is destroyed and the resulting fragments expand at a much reduced velocity.

The internal details of the $\mathrm{S} \& \mathrm{~A}$ device are given in Figure 2. Comparing the dimensions of the detonator shows that the threaded portion mates with the housing while the output portion is not supported. Thus, the $S \&$ A housing does not provide any additional support for the detonator explosive column. This suggests that the characterization testing may be done with the output section exposed.

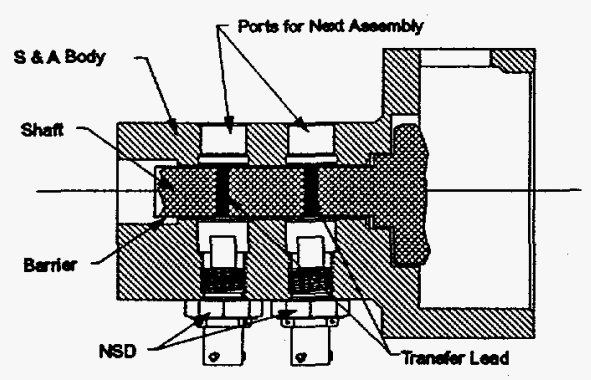

Figure 2. Internal Detalls of $5 \&$ A Device

\section{Description of Experiments}

All of the experiments discussed here involve either flash X-ray or velocity interferometry. One of the tests used both devices to provide simultaneous measurements. Brief descriptions of each apparatus are given below.

\section{Flash X-ray}

The flash X-ray system is designed to provide "stop-motion" photographs of high velocity objects. The advantage of this technique over conventional photography is that no external light source is required, smoke and self-light do not obscure the target, and multiple images can be obtained on a single frame. The arrangement of the equipment is shown in Figure 3. Five individual $150 \mathrm{kV}$ pulsers ${ }^{3}$ are arrayed in a vertical plane, oriented so that the output beams intersect at the target. Lead 
apertures are use to control the vertical width of the individual beams. A single plate of film (approximately $11^{\prime \prime}$ by $17^{\prime}$ ) is placed in a protective housing on the opposite side of the device under test. Normal spacing is $88^{\prime \prime}$ from the pulser to target and $8^{\mathrm{N}}$ from the target to the film plane. Because of the orientation of the heads, only one view on the film provides a true sideprofile of non-cylindrical objects.

The pulse width of the $\mathrm{X}$-ray exposure is approximately $40 \mathrm{~ns}$ at half-maximum amplitude. The interframe time interval is infinitely adjustable by means of time delay generators. The pulsers must be triggered from a source that is timecorrelated to some event in the detonator function. Typically, a TOAD pin ${ }^{4}$ is placed against the side of the output column to provide a signal ahead of the beginning of movement. The position must provide a minimum of $1.2 \mu \mathrm{s}$ lead time to account for the delays through the cabling and equipment. Thus, a zero delay generator setting will cause the pulser to expose the film approximately $1.2 \mu \mathrm{s}$ after the TOAD signal.

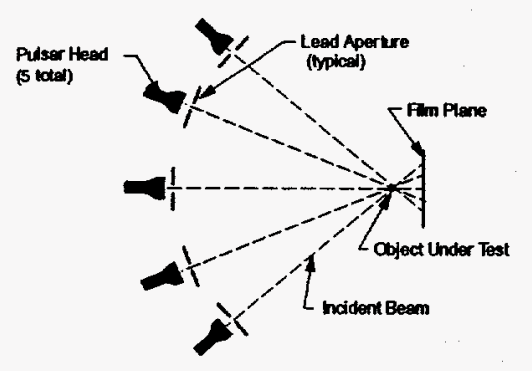

Figure 3. Layout of Flash X-ray Equipment

\section{VISAR}

The Velocity Interferometer System for Any Reflector (VISAR) ${ }^{5}$ measures the velocity of a moving object by detecting the Doppler shift in the laser light frequency induced by the motion of the target. The equipment used here is a "dual-leg"6 system that provides two separate and independent measurements from a single laser source. Prior to a test, the end closure of the detonator is treated by lightly abrading the surface with a media blaster to provide a diffuse-reflecting image. The laser light is focused onto the surface with a 13 " focal length lens to give good depth of field for the flyer motion.

The resolution of the VISAR is governed principally by the bandpass of the electronics that convert the light level information into corresponding electrical signals. For $400 \mathrm{MHz}$ amplifiers, the time resolution is on the order of $1 / 2$ ns. The digitizers record data at a sampling rate of 1 gigasample per second, or $1 \mathrm{~ns}$ per point. This response allows the instrument to observe fine details of the motion of the target surface.

In the flyer velocity tests, a $1 / 2$ " thick Lexan ${ }^{\star}$ sheet was placed in the path of the flying plate, in a plane orthogonal to the axis of the detonator. The separation distance from the face of the unit was 1". The Lexan ${ }^{\circ}$ was used as a witness plate for the impact of the flyer and debris. It also provided a distinct demarcation on the velocity record to compare the resolved distance to the position of the plate.

\section{$\underline{\text { Results }}$}

Six experiments were completed on the detonator, all used VISAR with the one also including flash $\mathrm{X}$-ray. Figure 4 is the flash $\mathrm{X}$-ray photograph of the flyer from a NSD. The detonator is seen in profile with the connector end on the right side of the metal fixture and a portion of the exposed output section to the left. As mentioned previously, all five views are of the same object, the apparent distortion coming from the orientation of each pulser head. Because the detonator body and the flyer are cylindrical, their profiles are essentially in true perspective. The light colored object to the left of the detonator fixture is the Lexan witness plate. In the top frame, the object coming down to the side of the output section is the TOAD pin used to provide the trigger source for the X-ray system. The known size of this device $\left(0.093^{\prime \prime}\right.$ in diameter) provides a reference for scaling other dimensions.

The hand-written numbers on the individual views are the times (in $\mu s$ ) that the pulser fired, all with respect to a fixed reference (the TOAD signal). In the first frame $(1.189 \mu \mathrm{s})$ the flyer is seen as the light colored, thin, membrane to the left of the output section. The X-ray image converts threedimensional object into two dimensional views. Because the amount of material is less into the 
plane of the film at the outer edge of the flyer, this region appears thinner. Measurements at the center of the object indicate a thickness of 20-mil, corresponding to the high end of the stated range.

The expanded body of the output housing can also be seen in the X-ray photo. The apparent position of the TOAD in the body is a distortion caused by the pin not being in the plane of this view. The light material directly behind and in contact with the flyer is the expansion of the explosive by products. The fact that all of the recognizable details are very symmetrical suggests that the detonator is behaving in a predictable fashion. The current position of the flyer relative to the starting location is unknown because the original location does not appear in any of the views. Thus, only relative displacement values can be obtained from one frame to the next.

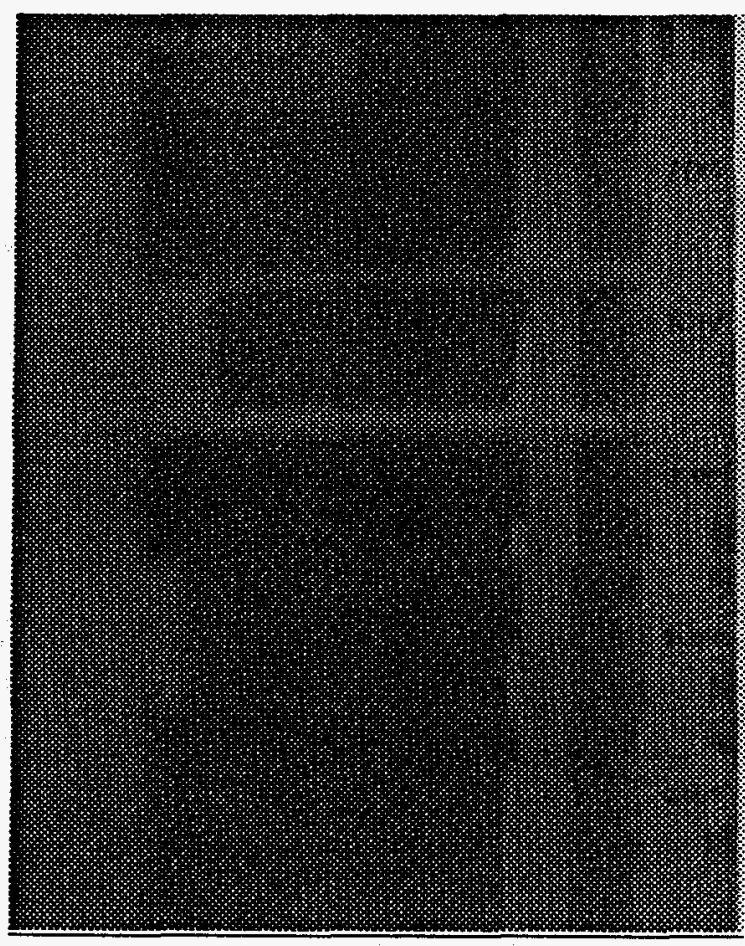

Figure 4. Flash X-ray Photograph of Detonator

The flash X-ray photographs also show the breakup of the metal housing of the output section. The outward growth of this section begins in the first view and continues throughout the recorded sequence. It is interesting to note that most of the movement of the fragments is outward with little material moving in the same direction of the flyer.
This suggests that most of the fragment impact on the witness plate is from the flyer and not the housing.

Table 1 gives the calculated displacements and velocities from this test. The velocities were obtained from the difference in the relative positions divided by the time interval. These results support the VISAR data reported below. The remaining views show the flyer to be well behaved in that it flies without tumbling or drastically changing shape. Close inspection, however indicates that it may not be intact but is a tightly-grouped field of fragments. This is deduced from the apparent "thickening" of flyer and the recession of the edges. Both of these trends manifest themselves as the fragments move apart with distance, even though the velocity is unaffected and the overall shape is normal. The thickness in the center region can also be developed if the disk becomes spherically deformed, but recession of the edges will not be manifested.

Table 1 Results From Flash X-ray Experiment

\begin{tabular}{|c|c|c|}
\hline Time $(\mu \mathrm{s})$ & Position $(\mathrm{mm})$ & $\begin{array}{c}\text { Velocity } \\
(\mathrm{mm} / \mu \mathrm{s})\end{array}$ \\
\hline 1.189 & 1.31 & $\mathrm{NA}$ \\
\hline 1.714 & 2.88 & 2.99 \\
\hline 2.051 & 3.95 & 3.16 \\
\hline 3.046 & 7.10 & 3.16 \\
\hline 4.065 & 10.34 & 3.08 \\
\hline
\end{tabular}

The results from a VISAR test are shown in Figure 5 , where the vertical axis is the velocity in $\mathrm{mm} / \mu \mathrm{s}$ and the horizontal axis is the time in $\mu s$. The beginning of the time reference is from the TOAD pin signal placed against the output section. The right-hand vertical axis is the displacement in $\mathbf{~ m m}$.

The show that the flyer has an instantaneous "Sump" in velocity to over $1.5 \mathrm{~mm} / \mu \mathrm{s}$. This is followed by a series of reverberations or oscillations as the shock wave propagates back and forth in the disk. Inspection of the time interval for each cycle shows that it corresponds to the shock velocity at that pressure divided into the compressed thickness of the disk. Typical time for one cycle is on the order of $100 \mathrm{~ns}$, yielding a thickness of about 10-15 mil for an assumed shock 
velocity of $5 \mathrm{~mm} / \mu \mathrm{s}$. While the oscillations are occurring, the velocity of the flyer continues to increase, but not as dramatically as the initial acceleration.

At a velocity just above $3.0 \mathrm{~mm} / \mu \mathrm{s}$, an abrupt increase occurs that does not match the previous more gradual acceleration trend. The cause for this behavior is unknown, however, using the displacement curve indicates that the propagation distance is about $2.2 \mathrm{~mm}$. This distance corresponds to the second view in Figure 4 (1.714 $\mu s$ ), or the possible onset of the breakup of the flyer. Comparison of the other tests shows similar behavior in most of the experiments. The final velocity of the flyer for this test is about 3.5 $\mathrm{mm} / \mu \mathrm{s}$, and is achieved shortly after the excursion described above. This velocity is nearly constant until the light level decreases so much that the signal-to-noise ratio becomes small.

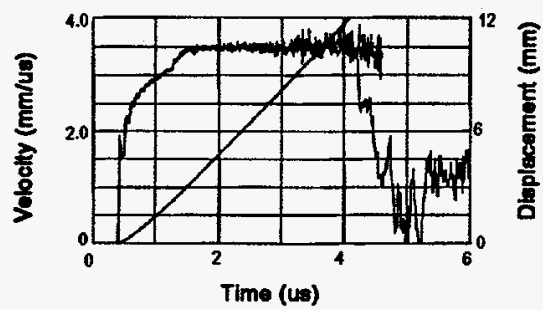

Figure 5. Velocity as a Function of Time Results

Comparison of three VISAR tests is given in Figure 6 in the form of velocity as a function of displacement. This shows that both the acceleration and final velocity vary from unit to unit. There is nearly a $10 \%$ variation in the velocity results for all detonator tests are given in Table 2. For two tests, a close fitting metal collar was added to the output section to determine if poor confinement was causing the erratic behavior. Both results compare closely with that shown in Figure 5, giving an initial conclusion that the lack of confinement in the detonator is not a significant contributing problem.
Table 2. Summary of VISAR Tests

\begin{tabular}{|c|c|c|l|}
\hline $\begin{array}{c}\text { Test } \\
\text { Number }\end{array}$ & $\begin{array}{c}\text { Det } \\
\text { S/N }\end{array}$ & $\begin{array}{c}\text { Final } \\
\text { Velocity } \\
(\mathrm{mm} / \mu \mathrm{s})\end{array}$ & Comments \\
\hline 1 & 35 & 3.5 & \\
\hline 2 & 12 & 3.4 & \\
\hline 3 & 41 & 3.2 & \\
\hline 4 & 51 & 3.3 & Collar added \\
\hline 5 & 50 & 3.5 & Collar added \\
\hline 6 & 73 & 3.2 & X-ray only \\
\hline
\end{tabular}

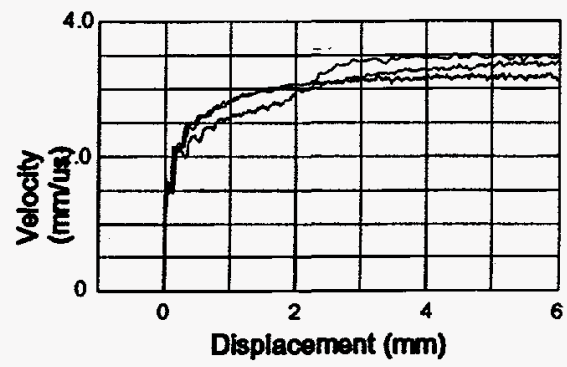

Figure 6. Comparison of Three Detonator Tests

\section{Conclusions}

A total of seven experiments were performed to characterize the NASA Standard Detonator. All tests used VISAR to measure the velocity of the metal plate created by the detonation of the explosive column. One test also used flash $\mathrm{X}$-ray to observe the nature of the flying disk. All units demonstrated the characteristic initial jump in velocity of the from the arrival of the detonation front. This was followed by a gradual acceleration to the final velocity. The final velocity varied from 3.2 to $3.5 \mathrm{~mm} / \mu \mathrm{s}$. Some units exhibited a second more gradual jump in velocity at about $2 \mathrm{~mm}$ propagation. The cause of this unexpected increase is unknown. The final velocity was maintained in most cases beyond $7 \mathrm{~mm}$, and was limited by the breakup of the flyer.

The NSD contains nearly $700 \mathrm{mg}$ of explosive in the detonator assembly alone. This large quantity allows it to accelerate a large metal disk to velocities in excess of $3 \mathrm{~mm} / \mu \mathrm{s}$. Designers should 
consider that the data indicate the flyer may breakup in distances as short as $2 \mathrm{~mm}$. Work is continuing on evaluating this component in the $S$ \& A used in the Space Shuttle and other applications.

\section{$\underline{\text { References }}$}

${ }^{1}$ Lauence J. Bement, et al., "Development of the NASA Standard Gas Generator (NSGG), " First NASA Pyrotechnic Systems Workshop, Houston TX, June 1992.

${ }^{2}$ B. M. Dobratz, LLNL Explosives Handbook, Lawrence Livermore Laboratory, Livermore, CA, Mar 1981.

${ }^{3}$ Field Emission Corp., Model 43731A, McMinnville, $\mathrm{OR}$.

4 Time Of Arrival Detector, manufactured by Dynasen Inc., Goleta Ca.

${ }^{5}$ L. M. Barker and R. E. Hollenbach, "Laser Interferometer for Measuring High Velocities of Any Reflecting Surface," J. Appl. Phys, Vol 43, No. 11, Nov 1972. 